\title{
Cardiovascular Disease and Gout: Real-World Experience Evaluating Patient Characteristics, Treatment Patterns, and Health Care Utilization
}

\author{
Michael H. Pillinger, MD; Sripal Bangalore, MD, MHA; Alyssa B. Klein, MPH; \\ Scott Baumgartner, MD; and Robert Morlock, PhD
}

\begin{abstract}
BACKGROUND: Gout, hyperuricemia, and cardiovascular disease (CVD) are prevalent conditions in the United States, and while they share common risk factors such as obesity, hypertension, hypercholesterolemia, and type 2 diabetes mellitus, relatively little is known about what patient and disease characteristics may link CVD with hyperuricemia and gout and how the presence of both diseases affects management decisions differently than for patients with gout alone.
\end{abstract}

OBJECTIVE: To identify differences in patient characteristics, patterns of urate-lowering therapy (ULT) use, and gout control in gout patients with and without cardiovascular comorbidity.

METHODS: Data were assessed from a survey of U.S. physicians who performed in-depth patient chart audits of their last 5 consecutive adult patients with confirmed gout as determined by the medical record and clinical notes. Comorbidities, gout symptoms, length of current treatment, sociodemographic factors, and physician type were identified from the chart review. Descriptive statistics and logistic regression described differences among patients with and without comorbid CVD and assessed ULT use and gout control.

RESULTS: Of the 1,159 patient charts that were reviewed, 738 patients had CVD and gout, and 421 had gout alone. Patients with CVD had longer duration of gout (mean [SD] $=52$ [68.2] vs. 34 [47.2] months; $P<0.001$ ) and were more likely to have clinician-reported tophi ( $28 \%$ vs. $15 \%$; $P<0.001)$, organ/ joint damage ( $19 \%$ vs. $9 \% ; P<0.001)$, and more flares $(2.1 \%$ vs. $1.8 \%$; $P=0.017$ ) in the previous 12 months. Time from gout diagnosis to start of ULT was delayed for those with CVD (mean [SD] = 24.3 [56.6] vs. 15.5 [33.2] months; $P=0.023$ ), but these patients were more likely to be receiving ULT ( $83 \%$ vs. $59 \%$; $P<0.001$ ). Gout patients with CVD were more likely to have a variety of additional comorbidities than those without CVD, such as obesity (28\% vs. $18 \%$; $P<0.001$ ), diabetes (26\% vs. $12 \% ; P<0.001)$, osteoarthritis (25\% vs. $11 \% ; P<0.001)$, chronic kidney disease (17\% vs. $5 \% ; P<0.001)$, and prostate disease (males, $\mathrm{n}=933 ; 10 \%$ vs. $2 \% ; P<0.001$ ). Gout patients with CVD were more likely to have an emergency department visit (12\% vs. $7 \% ; P=0.003$ ) for gout in the previous 12 months. In patients with CVD, ULT use was associated with better gout control.

CONCLUSIONS: Gout patients with CVD were more likely to have additional comorbidities, more gout-related symptoms, and a delay in initiating treatment, which may be associated with the greater severity of disease in these patients. These data suggest that gout patients with CVD may constitute a less healthy group in need of earlier, more aggressive therapy.

J Manag Care Spec Pharm. 2017;23(6):677-83

Copyright $\odot 2017$, Academy of Managed Care Pharmacy. All rights reserved.

\section{What is already known about this subject}

Gout is poorly managed, but the reasons for management insufficiency are not fully understood.

Patients with gout have increased cardiovascular disease (CVD) compared with the general population, but not all patients with gout have CVD.

\section{What this study adds}

In this analysis, all gout patients were generally poorly controlled. Gout patients with CVD had additional comorbidities and had greater emergency department visits for gout.

Study results suggest that CVD in gout patients may serve as a clinical marker for more careful monitoring and earlier initiation of treatment for gout.

Trnth n the United States, an estimated 8.3 million (4\%) adults are affected by gout; 43.3 million (21\%) have hyperuricemia; and 85.6 million (>1 in 3) have cardiovascular disease (CVD). ${ }^{1,2}$ Among patients with gout, $74 \%$ have been shown to have concomitant hypertension; 14\% have had a myocardial infarction; $11 \%$ have heart failure; and 10\% have suffered a stroke. ${ }^{3}$ Increased risk of CVD-related death and fatal coronary heart disease, as well as all-cause mortality, have also been observed in those with hyperuricemia versus those without., Elevated levels of serum uric acid (sUA) have been linked to CVD for more than a century, ${ }^{6}$ and while numerous epidemiologic studies have shown that patients with gout are more likely to have CVD and to have CVD-related sequelae, ${ }^{3-5}$ relatively little is known about what links CVD and hyperuricemia.

Obesity, hypertension, hypercholesterolemia, and type 2 diabetes mellitus are known risk factors for CVD, and each of these risk factors is also associated with a greater incidence of hyperuricemia. ${ }^{7-10}$ A large study that evaluated sUA levels over time in adult patients demonstrated that, after 6 years of follow-up, better cardiovascular health status was associated with a lower occurrence of hyperuricemia. ${ }^{11}$ Moreover, higher health care and productivity costs have been observed in 
Cardiovascular Disease and Gout: Real-World Experience Evaluating

Patient Characteristics, Treatment Patterns, and Health Care Utilization

TABLE 1 Characteristics of the Study Population

\begin{tabular}{|c|c|c|c|c|c|c|}
\hline \multirow{2}{*}{$\begin{array}{l}\text { Characteristic } \\
\text { Male, \% (n) [95\% CI] }\end{array}$} & \multicolumn{2}{|c|}{$\begin{array}{l}\text { With Comorbid CVD } \\
\qquad(\mathrm{n}=738)\end{array}$} & \multicolumn{3}{|c|}{$\begin{array}{l}\text { Without CVD } \\
\quad(n=421)\end{array}$} & \multirow{2}{*}{$\frac{P \text { Value }}{0.889}$} \\
\hline & $80.6 \quad(595)$ & {$[77.8-83.5]$} & 80.3 & $(338)$ & {$[76.5-84.1]$} & \\
\hline White, \% (n) [95\% CI] & $73.3(541)$ & {$[70.1-76.5]$} & 67.5 & $(284)$ & {$[63.0-72.0]$} & 0.035 \\
\hline Aged $\geq 61$ years, $\%(n)[95 \% C I]$ & $46.5 \quad(343)$ & {$[42.9-50.1]$} & 23.3 & (98) & {$[19.2-27.3]$} & $<0.001$ \\
\hline Treated by PCP (vs. rheumatologist), \% (n) [95\% CI] & $51.9 \quad(383)$ & [48.3-55.5] & 49.6 & $(209)$ & [44.9-54.4] & 0.461 \\
\hline Months since first gout diagnosis, mean (SD) [95\% CI] & $52.0(68.2)$ & {$[47.1-56.9]$} & 33.6 & $(47.2)$ & {$[29.0-38.1]$} & $<0.001$ \\
\hline sUA at diagnosis, mean mg/dL (SD) [95\% CI] & $9.4 \quad(2.1)$ & [9.3-9.6] & 9.4 & $(2.3)$ & {$[9.2-9.7]$} & 0.950 \\
\hline Average sUA previous 12 months, mg/dL, (SD) [95\% CI] & $7.3 \quad(1.9)$ & [7.1-7.4] & 7.4 & $(1.9)$ & {$[7.2-7.6]$} & 0.359 \\
\hline Number of flares in previous 12 months, mean (SD) [95\% CI] & $2.1 \quad(2.1)$ & [1.9-2.2] & 1.8 & (1.9) & [1.6-1.9] & 0.017 \\
\hline Tophi, \% (n) [95\% CI] & $28.3(209)$ & {$[25.1-31.6]$} & 15.2 & $(64)$ & {$[11.8-18.7]$} & $<0.001$ \\
\hline Joint damage, \% (n) [95\% CI] & $19.1 \quad(141)$ & {$[16.3-22.0]$} & 8.6 & $(36)$ & {$[5.9-11.2]$} & $<0.001$ \\
\hline Chronic pain, \% (n) $[95 \% \mathrm{CI}]$ & $4.3 \quad(32)$ & {$[2.9-5.8]$} & 2.9 & (12) & [1.3-4.5] & 0.203 \\
\hline Commercial insurance, \% (n) $[95 \%$ CI] & $55.8 \quad(412)$ & {$[52.2-59.4]$} & 68.4 & $(288)$ & {$[64.0-72.9]$} & $<0.001$ \\
\hline Low social economic status, \% (n) [95\% CI] & $26.4 \quad(195)$ & {$[23.2-29.6]$} & 17.3 & $(73)$ & {$[13.7-21.0]$} & $<0.001$ \\
\hline Alcoholism, \% (n) [95\% CI] & $10.6 \quad(78)$ & {$[8.3-12.8]$} & 14.0 & $(59)$ & {$[10.7-17.3]$} & 0.081 \\
\hline Chronic kidney disease, \% (n) [95\% CI] & $17.5 \quad(129)$ & {$[14.7-20.2]$} & 5.0 & $(21)$ & [2.9-7.1] & $<0.001$ \\
\hline Depression, \% (n) [95\% CI] & $14.9 \quad(110)$ & {$[12.3-17.5]$} & 12.6 & (53) & [9.4-15.8] & 0.276 \\
\hline Diabetes, \% (n) [95\% CI] & $26.4 \quad(195)$ & {$[23.2-29.6]$} & 12.1 & $(51)$ & {$[9.0-15.2]$} & $<0.001$ \\
\hline Kidney stones, \% (n) [95\% CI] & (54) & {$[5.4-9.2]$} & 2.9 & (12) & {$[1.3-4.4]$} & 0.002 \\
\hline Males with prostate disease, a \% (n) $[95 \%$ CI] & $(61)$ & [6.3-10.3] & 1.7 & $(7)$ & {$[0.4-2.9]$} & $<0.001$ \\
\hline Obesity, \% (n) [95\% CI] & $28.2 \quad(208)$ & {$[24.9-31.4]$} & 18.3 & $(77)$ & {$[14.6-22.0]$} & $<0.001$ \\
\hline Osteoarthritis, \% (n) [95\% CI] & $25.1 \quad(185)$ & {$[21.9-28.2]$} & 10.7 & $(45)$ & {$[7.7-13.7]$} & $<0.001$ \\
\hline Good/excellent QoL, \% (n) [95\% CI] & $68.3 \quad(504)$ & {$[64.9-71.7]$} & 73.4 & $(309)$ & {$[69.2-77.6]$} & 0.068 \\
\hline Presence of chronic pain, \% (n) [95\% CI] & $(32)$ & {$[2.9-5.8]$} & 2.9 & $(12)$ & {$[1.3-4.5]$} & 0.203 \\
\hline
\end{tabular}

patients with gout who also have a history of CVD, compared with those who do not. ${ }^{12}$

This study was designed to identify predictors of uratelowering therapy (ULT) use and gout control in patients with and without CVD comorbidity.

\section{Methods}

\section{Data Collection and Analysis}

Data were assessed from detailed and systematic patient chart audits carried out in October 2012. ${ }^{13}$ To qualify for inclusion in this study, clinicians had to (a) have been in practice for between 2 and 30 years, (b) spend more than $75 \%$ of their time in the clinic, and (c) manage the care of $\geq 50$ patients with gout annually. Physicians received financial compensation for participating. Physicians who elected to participate performed a chart audit of their last 5 consecutive adult patients with confirmed gout as determined by the medical record and clinical notes. Patients were considered to have comorbid CVD if a history of CVD was listed in the patients' charts ("cardiovascular disease" and/or "congestive heart failure" and/or "hyperlipidemia" and/or "hypertension"). Physicians completed a structured case report form for each patient, which encompassed the previous 12 months and comprised sUA laboratory values, flare counts, physician-classified tophi, comorbidities (including CVD), type and dose of xanthine oxidase inhibitor (XOI; allopurinol or febuxostat), length of current treatment, previous treatments, diagnosis date, patient social and demographic factors, and physician type. Because ULT may result in a reduction of treatmentrelated flares, patients at sUA target $(\leq 6 \mathrm{mg} / \mathrm{dL})$ and having $\leq 1$ flare in the study period were considered fully controlled.

Data collection was in compliance with the Health Insurance Portability and Accountability Act. Because this study was based on a dataset that was previously recorded and de-identified, and no codes were available to re-identify the patients, it met the standard for exemption from requiring independent institutional review board approval.

\section{Statistical Methodology}

Descriptive statistics were used to evaluate the differences among patients with and without CVD and to assess gout control and ULT use, which was limited to the XOIs allopurinol and febuxostat. Bivariate comparisons using t-tests for 
Cardiovascular Disease and Gout: Real-World Experience Evaluating

Patient Characteristics, Treatment Patterns, and Health Care Utilization

\section{TABLE 2 Odds Ratios of Multivariate Predictors of ULT Use for Patients with and Without CVD}

\begin{tabular}{|c|c|c|}
\hline \multicolumn{3}{|l|}{ Patients with CVD } \\
\hline Characteristic & $\begin{array}{c}\text { With Comorbid CVD } \\
\text { OR }(95 \% \mathrm{CI}) \\
(\mathbf{n}=738)\end{array}$ & $P$ Value \\
\hline Male (vs. female) & $2.36 \quad(1.38-4.04)$ & 0.002 \\
\hline White (vs. nonwhite) & $1.32 \quad(0.82-2.14)$ & 0.255 \\
\hline Aged $\geq 61$ years (vs. $<61$ years) & $0.89 \quad(0.54-1.49)$ & 0.664 \\
\hline Treated by PCP (vs. rheumatologist) & $0.27 \quad(0.16-0.44)$ & $<0.001$ \\
\hline Months since diagnosis & $1.00 \quad(1.00-1.01)$ & 0.615 \\
\hline Flares in past 12 months & $0.83 \quad(0.74-0.92)$ & 0.001 \\
\hline Tophi & $2.40 \quad(1.13-5.09)$ & 0.023 \\
\hline Joint damage & $4.52 \quad(1.30-15.70)$ & 0.018 \\
\hline Chronic pain & $3.60 \quad(0.42-31.19)$ & 0.246 \\
\hline Commercial insurance & $1.04 \quad(0.61-1.78)$ & 0.882 \\
\hline Low social economic status & $0.70 \quad(0.42-1.17)$ & 0.172 \\
\hline Alcoholism & $2.00 \quad(0.73-5.52)$ & 0.178 \\
\hline Chronic kidney disease & $1.87 \quad(0.81-4.33)$ & 0.145 \\
\hline Depression & $1.33 \quad(0.68-2.57)$ & 0.401 \\
\hline Diabetes & $1.29 \quad(0.75-2.22)$ & 0.359 \\
\hline Kidney stones & $1.35 \quad(0.47-3.86)$ & 0.572 \\
\hline Males with prostate disease ${ }^{a}$ & $2.80 \quad(0.78-9.71)$ & 0.115 \\
\hline Obesity & $1.39 \quad(0.83-2.34)$ & 0.21 \\
\hline Osteoarthritis & $1.82 \quad(0.92-1.82)$ & 0.087 \\
\hline
\end{tabular}

\begin{tabular}{|c|c|c|}
\hline \multicolumn{3}{|l|}{ B. Patients Without CVD } \\
\hline \multirow{2}{*}{$\begin{array}{l}\text { Characteristic } \\
\text { Male (vs. female) }\end{array}$} & $\begin{array}{c}\text { Without Comorbid CVD } \\
\text { OR }(95 \% \mathrm{CI}) \\
(\mathrm{n}=738)\end{array}$ & \multirow{2}{*}{$\frac{P \text { Value }}{0.064}$} \\
\hline & $1.69 \quad(0.97-2.95)$ & \\
\hline White (vs. nonwhite) & $0.76 \quad(0.47-1.22)$ & 0.259 \\
\hline Aged $\geq 61$ years (vs. $<61$ years) & $0.76 \quad(0.41-1.44)$ & 0.404 \\
\hline Treated by PCP (vs. rheumatologist) & $0.37 \quad(0.24-0.59)$ & $<0.001$ \\
\hline Months since diagnosis & $1.00 \quad(1.00-1.01)$ & 0.480 \\
\hline Flares in past 12 months & $1.047(0.92-1.19)$ & 0.473 \\
\hline Tophi & $7.47 \quad(2.78-20.09)$ & $<0.001$ \\
\hline Joint damage & $0.98 \quad(0.37-2.62)$ & 0.966 \\
\hline Chronic pain & $0.18 \quad(0.04-0.82)$ & 0.027 \\
\hline Commercial insurance & $1.14 \quad(0.65-2.03)$ & 0.647 \\
\hline Low social economic status & $1.10 \quad(0.59-2.05)$ & 0.762 \\
\hline Alcoholism & $0.93 \quad(0.49-1.78)$ & 0.816 \\
\hline Chronic kidney disease & $2.03 \quad(0.64-6.39)$ & 0.227 \\
\hline Depression & $1.31 \quad(0.65-2.65)$ & 0.457 \\
\hline Diabetes & $2.72 \quad(1.21-5.15)$ & 0.016 \\
\hline Males with prostate disease ${ }^{a}$ & $2.47 \quad(0.36-17.0)$ & 0.357 \\
\hline Obesity & $1.43 \quad(0.79-2.57)$ & 0.237 \\
\hline Osteoarthritis & $1.59 \quad(0.69-3.66)$ & 0.276 \\
\hline
\end{tabular}

$a_{n}=933$.

$C I=$ confidence interval $; C V D=$ cardiovascular disease; $O R=$ odds ratio; $P C P=$ primary care physician; $U L T=$ urate-lowering therapy.

comparisons were conducted on continuous variables (e.g., sUA levels) between the 2 groups. For categorical variables (e.g., demographic characteristics), chi-square tests were conducted. Symptom levels captured as categories and correlations between levels of flares, tophi, and sUA were computed using Spearman's rho.

Use of ULT and gout control were assessed using a multivariate logistic model. Model covariates included age, sex, comorbid conditions, XOI use, tophi, duration on current ULT, and insurance type. Because score distributions were found to be normally distributed, no transformation was applied.

\section{Results}

The database used for this study included data abstracted by 125 primary care physicians and 125 rheumatologists. Information from a total of 1,159 gout patient charts was available for analysis, including 738 with comorbid CVD and 421 without comorbid CVD (Table 1). The majority of patients were male (80.5\%) and white $(71.2 \%)$, with no differences in the proportions of each sex between groups, but the proportion of white patients was different between those with and without CVD disease (73.3\% vs. $67.5 \% ; P=0.035$ ). While $38.1 \%$ of all gout patients were aged $\geq 61$ years, a greater percentage of patients among those with comorbid CVD were aged $\geq 61$ years, compared with those without comorbid CVD ( $46.5 \%$ vs. $23.3 \%$; $P<0.001)$. No difference was observed in sUA levels at the time of gout diagnosis ( 9.4 vs. $9.4 \mathrm{mg} / \mathrm{dL} ; P=0.950$ ) or mean (standard deviation [SD]) sUA levels over the previous year (7.3 [1.9] vs. 7.4 [1.9] mg/dL; $P=0.359$ ).

Gout patients with comorbid CVD were more likely to have a variety of additional medical conditions, compared with those without CVD (Table 1), including chronic kidney disease (CKD; $18 \%$ vs. $5 \%$; $P<0.001$ ), diabetes (26\% vs. $12 \%$; $P<0.001$ ), obesity (28\% vs. $18 \%$; $P<0.001$ ), osteoarthritis ( $25 \%$ vs. $11 \% ; P<0.001$ ), and prostate disease (males, $n=933 ; 8 \%$ vs. $2 \% ; P<0.001$ ). Alcoholism and depression were not statistically significantly different between the 2 groups.

Patients with comorbid CVD demonstrated different goutrelated disease characteristics than those without CVD (Table 1). They had longer mean (SD) duration of gout (52 [68.2] vs. 34 [47.2] months; $P<0.001)$, were more likely to have clinicianreported joint damage (19\% vs. $9 \% ; P<0.001$ ), tophi ( $28 \%$ vs. $15 \% ; P<0.001$ ), and flares in the previous 12 months (mean $[S D]=2.1[2.1]$ vs. $1.8[1.9] ; P=0.017)$. Statistically significant differences were not observed in the proportion of patients with good or excellent quality of life as assessed by the clinician $(68.3 \%$ vs. $73.4 \% ; P=0.068)$ or who had chronic pain ( $4.3 \%$ vs. $2.9 \% ; P=0.203)$. 


\begin{tabular}{|c|c|c|}
\hline \multirow[b]{2}{*}{ Characteristic } & $\begin{array}{l}\text { of Multivariate P } \\
\text { rol for Patients }\end{array}$ & $\begin{array}{l}\text { ictors } \\
\text { CVD }\end{array}$ \\
\hline & $\begin{array}{c}\text { With Comorbid CVD } \\
\text { OR }(95 \% \text { CI }) \\
(n=738) \\
\end{array}$ & $P$ Value \\
\hline ULT use (vs. no ULT use) & $2.38(1.39-4.09)$ & 0.002 \\
\hline Male (vs. female) & $0.94 \quad(0.59-1.51)$ & 0.800 \\
\hline White (vs. nonwhite) & $1.18 \quad(0.79-1.76)$ & 0.421 \\
\hline Aged $\geq 61$ years (vs. $<61$ years) & $0.82(0.54-1.24)$ & 0.355 \\
\hline Treated by PCP (vs. rheumatologist) & $0.83 \quad(0.57-1.93)$ & 0.308 \\
\hline Months since diagnosis & $1.00(1.00-1.01)$ & 0.019 \\
\hline Tophi & $0.65 \quad(0.41-1.03)$ & 0.066 \\
\hline Joint damage & $0.74 \quad(0.44-1.25)$ & 0.256 \\
\hline Chronic pain & $0.10 \quad(0.01-0.77)$ & 0.027 \\
\hline Commercial insurance & $0.69 \quad(0.45-1.04)$ & 0.076 \\
\hline Low social economic status & $0.97 \quad(0.64-1.47)$ & 0.889 \\
\hline Alcoholism & $0.96 \quad(0.53-1.73)$ & 0.880 \\
\hline Chronic kidney disease & $0.74 \quad(0.44-1.22)$ & 0.235 \\
\hline Depression & $0.48 \quad(0.28-0.85)$ & 0.011 \\
\hline Diabetes & $1.19 \quad(0.80-1.77)$ & 0.402 \\
\hline Kidney stones & $0.76 \quad(0.38-1.54)$ & 0.447 \\
\hline Males with prostate disease ${ }^{a}$ & $1.44 \quad(0.77-2.66)$ & 0.252 \\
\hline Obesity & $0.92 \quad(0.62-1.38)$ & 0.694 \\
\hline Osteoarthritis & $1.68(1.10-2.58)$ & 0.017 \\
\hline $\begin{array}{l}a_{n}=933 . \\
C I=\text { confidence inter } \\
P C P=\text { primary care }\end{array}$ & $\begin{array}{l}\text { Ir disease; } O R=\text { odds } \\
\text { wering therapy. }\end{array}$ & \\
\hline
\end{tabular}

Differences in gout treatment patterns were also observed between those with comorbid CVD and those without. Mean (SD) time from gout diagnosis to start of ULT was delayed for those with CVD (24.3 [56.6] vs. 15.5 [33.2] months; $P=0.023$ ), but patients with comorbid CVD were more likely to be receiving ULT $(82.7 \%$ vs. $59.1 \%$; $P<0.001)$. Patients with comorbid CVD were more likely to have an emergency department visit for gout in the previous 12 months $(12.3 \%$ vs. $6.9 \%$; $P=0.003)$. There was also a greater risk of hospitalization for gout (3.1\% vs. $1.9 \% ; P=0.217)$ and surgery for gout $(1.1 \%$ vs. $0.2 \% ; P=0.115)$ over this time frame. The proportions of patients with or without CVD comorbidity whose gout were being treated by a primary care physician $(51.9 \%$ vs. $49.6 \%$; $P=0.461)$ or a rheumatologist (48.1\% vs. $50.4 \%$; $P=0.461)$ were similar.

A logistic regression (Table 2A) found that patients with comorbid CVD were more likely to be treated with ULT if they were male (odds ratio $[O R]=2.36$ ), had tophi $(O R=2.40)$, or had joint damage $(\mathrm{OR}=4.52)$ and less likely to be treated with ULT if care was managed by a primary care physician versus a rheumatologist $(\mathrm{OR}=0.27)$ or reporting more flares over the previous 12 months $(\mathrm{OR}=0.83)$. A separate logistic regression (Table 2B) found that patients without comorbid CVD were more likely to be treated with ULT if they had tophi $(\mathrm{OR}=7.5)$ or diabetes $(\mathrm{OR}=2.72)$ and less likely to be treated with ULT if care was managed by a primary care physician versus a rheumatologist $(\mathrm{OR}=0.37)$ or they had chronic pain $(\mathrm{OR}=0.18)$.

To assess gout control in those with comorbid CVD disease, a logistic model predicting control (Table 3) found that ULT use $(\mathrm{OR}=2.38)$, the presence of osteoarthritis $(\mathrm{OR}=1.68)$, and time since the initial gout diagnosis $(\mathrm{OR}=1.00)$ were predictive of gout control. Chronic pain $(\mathrm{OR}=0.10)$ and the presence of depression $(\mathrm{OR}=0.48)$ were predictive of not being in control.

Use of ULT was associated with better gout control in gout patients with CVD. Table 4 shows the differences in the percentage of patients who achieved measures of treatment control stratified by ULT use. Regardless of comorbid CVD status, the percentage of patients with sUA at goal $(\leq 6 \mathrm{mg} / \mathrm{dL})$ or who experienced no flares in the previous year was greater in patients using ULT, and patients using ULT had significantly lower sUA levels at last measurement.

\section{Discussion}

To our knowledge, this is one of the first studies to examine differences in patient, disease, and treatment characteristics between gout patients with and without CVD. In this analysis, differences in treatment patterns emerged between gout patients with and without comorbid CVD. Time from gout diagnosis to start of ULT was delayed for those with comorbid CVD; however, patients with comorbid CVD were more likely to be receiving ULT. Patients with comorbid CVD were also more likely to have received treatment for gout in an emergency department. Patients with CVD were more likely to receive ULT, and the specific characteristics associated with ULT use differed between those with CVD comorbidity and those without. While being treated by a rheumatologist and having tophi were predictive in those with or without CVD, having flares or joint damage were also predictive of ULT use only in gout patients with comorbid CVD. It is unclear why these differences were observed.

Given the increased presence of known risk factors associated with gout (advanced age and presence of other debilitating diseases such as diabetes, CKD, and osteoarthritis), gout patients with comorbid CVD may constitute a less healthy group who may be candidates for earlier, more aggressive therapy. Additionally, our data showed that ULT use was predictive of gout symptom control only in patients with CVD.

The observation in this analysis-that treatment was delayed in those with comorbid CVD_may reflect reluctance by physicians to initiate ULT in patients with other health conditions for fear of poor tolerability, potential adverse reactions, polypharmacy, or noncompliance. This delay did not preclude 
Cardiovascular Disease and Gout: Real-World Experience Evaluating

Patient Characteristics, Treatment Patterns, and Health Care Utilization

TABLE 4 Gout Control in Patients Treated with ULT Compared with Patients Without ULT

\begin{tabular}{|c|c|c|c|c|c|c|}
\hline & \multicolumn{3}{|c|}{ With Comorbid CVD $(n=738)$} & \multicolumn{3}{|c|}{ Without Comorbid CVD $(n=421)$} \\
\hline & $\begin{array}{l}\text { ULT Use } \\
(\mathrm{n}=610)\end{array}$ & $\begin{array}{l}\text { No ULT Use } \\
(\mathrm{n}=128)\end{array}$ & $P$ Value & $\begin{array}{l}\text { ULT Use } \\
(n=249)\end{array}$ & $\begin{array}{l}\text { No ULT Use } \\
\quad(n=172)\end{array}$ & $P$ Value \\
\hline sUA at goal, a \% (n) $[95 \%$ CI] & $45.7(279)[41.8-49.7]$ & 25.0 (32) [17.4-32.6] & $<0.001$ & 45.4 (113) [39.2-51.6] & $29.1 \quad(50)[22.2-35.9]$ & 0.001 \\
\hline No flares, \% (n) [95\% CI] & $23.0(140)[19.6-26.3]$ & $11.7(15) \quad[6.1-17.4]$ & 0.005 & $27.3 \quad(68) \quad[21.7-32.9]$ & $17.4 \quad(30) \quad[11.7-23.2]$ & 0.018 \\
\hline $\begin{array}{l}\text { sUA at goal a and } \leq 1 \text { gout-related } \\
\text { flares, } \%(n)[95 \% \text { CI }]\end{array}$ & $29.7(181)[26.0-33.3]$ & $15.6(20) \quad[9.3-22.0]$ & 0.001 & $27.3 \quad(68) \quad[21.7-32.9]$ & $20.4 \quad$ (35) $[14.3-26.4]$ & 0.103 \\
\hline $\begin{array}{l}\text { Most recent sUA level, mean } \\
\mathrm{mg} / \mathrm{dL}(\mathrm{SD})[95 \% \mathrm{CI}]\end{array}$ & $6.6(1.8) \quad[6.5-6.8]$ & $7.5(2.5) \quad[7.0-7.9]$ & $<0.001$ & $6.8(2.2) \quad[6.6-7.1]$ & $7.4(2.0) \quad[7.1-7.7]$ & 0.006 \\
\hline
\end{tabular}

patients from receiving ULT once initiated, since patients with CVD were more likely receiving ULT, which may reflect the more severe nature of their symptoms. Conversely, the delay in treatment may have been the cause, rather than the consequence, of increased comorbidity. Nevertheless, studies have not shown a correlation between increased risk of adverse events and comorbidities related to ULT use in patients with gout. Rather, studies have shown that ULT can have positive benefits on the incidence of comorbidities, particularly CVD. Two recent and large case-matched cohort studies found that patients with hyperuricemia with or without a diagnosis of gout who were treated with ULT (allopurinol or benzbromarone) exhibited significantly lower risk of CVD-related and all-cause mortality. ${ }^{14,15}$ Also, a pilot study of febuxostat in hyperuricemic patients with hypertension found that febuxostat treatment suppressed the renin-angiotensin-aldosterone system and improved renal function, which may have beneficial effects on CVD risk. ${ }^{16}$

\section{Limitations}

Limitations of this study are intrinsic to retrospective chart reviews and include the absence of independent confirmation of data and the potential for physician and patient selection bias. We would have liked to assess the extent of this possible bias by reviewing patient charts directly but could not because the dataset was fully anonymized at the time of our evaluation. However, the physicians who chose to participate may have had a greater interest in the condition or saw more patients with gout than those who did not. Those with an interest in the topic may also have taken more care when responding to the survey than they otherwise would have. Since physicians were asked to review the charts of their last 5 consecutive patients with gout, their recollection may have been skewed to identifying and including patients with more gout-related symptoms. On the other hand, since comparisons were made across characteristics, bias introduced by gout disease severity should have been reduced. Because all of the data were entered in the charts by physicians rather than the patients, the data may not have accurately and fully reflected the patients' experiences. However, our methodology was consistent with other studies and clinical practice.

Furthermore, adherence by patients to medication was not assessed, so effects of ULT on gout control may be misrepresented. This lack of adherence assessment is a serious concern because patients with comorbid CVD may be receiving multiple medications, and studies have shown that, for a variety of chronic diseases, as the complexity of treatment regimens increases, adherence decreases. ${ }^{17-21}$ On the other hand, one study reported that among gout patients, adherence was greater when patients had more comorbidities. ${ }^{22}$ Finally, although the definition of gout control used in this analysis represented the ideal case scenario and was consistent with current management guidelines, ${ }^{23-25}$ it may have been subjective and did not indicate improvement in individual parameters (e.g., sUA levels, joint/organ damage, and tophi); however, individual parameters were analyzed separately.

\section{Conclusions}

Patients with gout often have comorbidities, particularly CVD, and many patients with and without comorbid CVD have poorly controlled gout. Our data indicate that gout patients with comorbid CVD are among those more likely to suffer additional comorbidities and experience delays in ULT initiation. Thus, CVD in gout patients may serve as a clinical marker for the need for gout treatment and the need to closely monitor an individual patient's situation. The majority of patients with gout are treated in the primary care setting; therefore, it is important that primary care practitioners have a good understanding of the many and complex factors that may affect management of this disease. 


\section{Authors}

MICHAEL H. PILLINGER, MD, Division of Rheumatology, and SRIPAL BANGALORE, MD, MHA, Division of Cardiology, New York University, New York, New York. ALYSSA B. KLEIN, MPH, AstraZeneca, Gaithersburg, Maryland; SCOTT BAUMGARTNER, MD, Ardea Biosciences, San Diego, California; and ROBERT MORLOCK, PhD, YourCareChoice, Ann Arbor, Michigan.

AUTHOR CORRESPONDENCE: Michael H. Pillinger, MD, Division of Rheumatology, New York University, 550 1st Ave., New York, NY 10016. Tel.: 212.263.5290; E-mail: Michael.pillinger@nyumc.org.

\section{DISCLOSURES}

This study was supported by AstraZeneca. Pillinger reports consultancies at AstraZeneca, SOBI, Crealta/Horizon; investigator-initiated grants from Takeda (closed 2016); and was an investigator on industry-sponsored clinical trials for Takeda. Klein is employed by AstraZeneca. At the time of this study, Baumgartner was employed by Ardea Biosciences, a wholly owned subsidiary of AstraZeneca and owns stock in AstraZeneca. Baumgartner and Morlock are consultants to Ardea Biosciences. Morlock reports consulting fees from Genentech, Ironwood Pharmaceuticals, Astellas, and Abbot Medical Optics outside of this study. Bangalore reports consultancies at Pfizer, Merck, Abbott Vascular, Medicines Company, AstraZeneca, and the National Heart, Lung, and Blood Institute. The authors did not receive any honoraria for this publication.

Study concept and design were primarily contributed by Morlock, along with the other authors. Morlock collected the data, and data interpretation was performed by all the authors. All authors equally contributed to preparation and revision of the manuscript.

Preliminary results from this study were presented at the AMCP Managed Care \& Specialty Pharmacy Annual Meeting 2016; San Francisco, California; April 19-22, 2016.

\section{ACKNOWLEDGMENTS}

The authors thank Meredith Rogers, MS, CMPP, of The Lockwood Group, for providing writing and editorial assistance, which was funded by AstraZeneca.

\section{REFERENCES}

1. Zhu Y, Pandya BJ, Choi HK. Prevalence of gout and hyperuricemia in the US general population: the National Health and Nutrition Examination Survey 2007-2008. Arthritis Rheum. 2011;63(10):3136-41.

2. Mozaffarian D, Benjamin EJ, Go AS, et al. Heart Disease and Stroke Statistics-2016 Update: a report from the American Heart Association. Circulation. 2016;133(4):e38-e360.

3. Zhu Y, Pandya BJ, Choi HK. Comorbidities of gout and hyperuricemia in the U.S. general population: NHANES 2007-2008. Am J Med.

2012;125(7):679-87.el

4. Kim SY, Guevara JP, Kim KM, Choi HK, Heitjan DF, Albert DA.

Hyperuricemia and coronary heart disease: a systematic review and metaanalysis. Arthritis Care Res (Hoboken). 2010;62(2):170-80
5. Choi HK, Curhan G. Independent impact of gout on mortality and risk for coronary heart disease. Circulation. 2007;116(8):894-900.

6. Kohn PM, Prozan GB. Hyperuricemia; relationship to hypercholesteremia and acute myocardial infarction. J Am Med Assoc. 1959;170(16):1909-12.

7. Ryu S, Chang Y, Zhang Y, et al. A cohort study of hyperuricemia in middle-aged South Korean men. Am J Epidemiol. 2012;175(2):133-43.

8. Yamada A, Sato KK, Kinuhata S, et al. Association of visceral fat and liver fat with hyperuricemia. Arthritis Care Res (Hoboken). 2016;68(4):553-61.

9. McAdams-DeMarco MA, Law A, Maynard JW, Coresh J, Baer AN. Risk factors for incident hyperuricemia during mid-adulthood in African American and white men and women enrolled in the ARIC cohort study. BMC Musculoskelet Disord. 2013;14:347.

10. Andrade JA, Kang HC, Greffin S, Garcia Rosa ML, Lugon JR. Serum uric acid and disorders of glucose metabolism: the role of glycosuria. Braz J Med Biol Res. 2014;47(10):917-23.

11. Li Z, Meng L, Huang Z, et al. Ideal cardiovascular health metrics and incident hyperuricemia. Arthritis Care Res (Hoboken). 2016;68(5):660-66.

12. Spaetgens B, Wijnands JM, van Durme C, van der Linden S, Boonen A. Cost of illness and determinants of costs among patients with gout. J Rheumatol. 2015;42(2):335-44.

13. Heap G, Sosa MP. Gout chart audit. BioTrends Research Group and Decision Resources Group. 2012

14. Chen JH, Lan JL, Cheng CF, et al. Effect of urate-lowering therapy on the risk of cardiovascular disease and all-cause mortality in patients with gout: a case-matched cohort study. J Rheumatol. 2015;42(9):1694-701.

15. Chen JH, Lan JL, Cheng CF, et al. Effect of urate-lowering therapy on all-cause and cardiovascular mortality in hyperuricemic patients without gout: a case-matched cohort study. PLoS One. 2015;10(12):e0145193.

16. Tani S, Nagao K, Hirayama A. Effect of febuxostat, a xanthine oxidase inhibitor, on cardiovascular risk in hyperuricemic patients with hypertension: a prospective, open-label, pilot study. Clin Drug Investig. 2015;35(12):823-31

17. Osterberg L, Blaschke T. Adherence to medication. N Engl J Med. 2005;353(5):487-97.

18. Mansur N, Weiss A, Beloosesky Y. Looking beyond polypharmacy: quantification of medication regimen complexity in the elderly. Am J Geriatr Pharmacother. 2012;10(4):223-29.

19. Sontakke S, Budania R, Bajait C, Jaiswal K, Pimpalkhute S. Evaluation of adherence to therapy in patients of chronic kidney disease. Indian J Pharmacol. 2015;47(6):668-71.

20. Knafl GJ, Riegel B. What puts heart failure patients at risk for poor medication adherence? Patient Prefer Adherence. 2014;8:1007-18.

21. Cantudo-Cuenca MR, Jimenez-Galan R, Almeida-Gonzalez CV, Morillo-Verdugo R. Concurrent use of comedications reduces adherence to antiretroviral therapy among HIV-infected patients. J Manag Care Spec Pharm. 2014;20(8):844-50. Available at: http://www.jmcp.org/doi/10.18553/ jmcp.2014.20.8.844.

22. Harrold LR, Andrade SE, Briesacher BA, et al. Adherence with urate-lowering therapies for the treatment of gout. Arthritis Res Ther. 2009;11(2):R46. 
23. Khanna D, Fitzgerald JD, Khanna PP, et al. 2012 American College of Rheumatology guidelines for management of gout. Part 1: systematic nonpharmacologic and pharmacologic therapeutic approaches to hyperuricemia Arthritis Care Res (Hoboken). 2012;64(10):1431-46.

24. Khanna D, Khanna PP, Fitzgerald JD, et al. 2012 American College of Rheumatology guidelines for management of gout. Part 2: therapy and antiinflammatory prophylaxis of acute gouty arthritis. Arthritis Care Res (Hoboken). 2012;64(10):1447-61.
25. Zhang W, Doherty M, Bardin T, et al. EULAR evidence based recommendations for gout. Part II: management. Report of a task force of the EULAR Standing Committee for International Clinical Studies Including Therapeutics (ESCISIT). Ann Rheum Dis. 2006;65(10):1312-24. 